\title{
Trauma-Informed Strategies to Support Complexly Traumatized Adolescents in Schools in the Time of the COVID-19 Pandemic
}

\author{
Elsa Márquez Aponte ${ }^{1}$
}

Complexly and collective traumatic experiences change the brain's structure and functioning. This affects children's and adolescents' perception and abilities to integrate information into a cohesive whole. It alters adolescents' developmental trajectory in seven domains including cognition, affect regulation, and behavioral control. These survivors need access to support systems to help them develop stable relationships that scaffold therapeutic practices to foster neuroplasticity, which facilitates coping and building resilience. Education policy reform addressing the need for courses in neuroeducation for complexly and collectively traumatized students in the aftermath of COVID-19, trauma-informed strategies and a systematic campaign to raise awareness are recommended. Additional research that focuses on adolescent trauma prevalence is necessary. [Article copies available for a fee from The Transformative Studies Institute. E-mail address: journal@transformativestudies.org Website: http://www.transformativestudies.org (C2020 by The Transformative Studies Institute. All rights reserved.]

KEYWORDS: Adolescent Development, Education, Policy, Reform, COVID-19, Identity, Trauma-Informed Strategies.

\section{INTRODUCTION}

Complex trauma, also known as developmental trauma or childhood adverse experiences (ACES), is a pervasive problem of epidemic proportions engendering academic failure, disease, and mortality. In neuroscience, psychology, and education, there has been an increasing

\footnotetext{
${ }^{1}$ Elsa Márquez Aponte is a graduate student at the Rutgers University School of Education, Learning, Cognition and Development program. She is also a teacher with 10 years of experience in a Title I, high school in the state of New Jersey. Her interest in developmental trauma derives from her own experience and working with a population affected by it. Address correspondence to: Elsa Márquez Aponte, e-mail: elsamarquezaponte@gmail.com
} 